\title{
A SEGUNDA BLOGNOVELA DA HISTÓRIA: AUTOBIOGRAFIA. IMPESSOAL. $O$ falso, possível tendência teatral contemporânea
}

\author{
Erlon Cherque Pinto ${ }^{1}$
}

\section{Resumo}

A SEGUNDA BLOGNOVELA DA HISTÓRIA: AUTOBIOGRAFIA. IMPESSOAL., de Erlon Cherque e Guilherme Miranda, apresentada uma vez em tempo real e gravada para transmissão online. Em lugar do novo, estabelece-se a dinâmica da diferença e negociação entre configurações estéticas teatrais. Tomando por base o Método Matricial (Jacó Guinsburg e Rubens Brito), estabeleceu-se o agrupamento de obras do encenador Gerald Thomas. A matriz criativa resultante: tendência ao falso. O elementoprocedimento de interesse para recriação da matriz criativa (tendência ao falso) foi a blognovela a partir do evento "A primeira blognovela da história: o cão que insultava mulheres, kepler, the dog". As categorias (metodologia, processo de criação e poética teatral) tornam-se posições temporárias e reversíveis no contexto da tendência ao falso.

Palavras-chave: Teatro Contemporâneo, Estética do Falso, Narrativas.

\section{Abstract}

THE SECOND BLOGNOVEL OF THE HISTORY: AUTOBIOGRAPHY. IMPERSONAL., (Erlon Cherque and Guilherme Miranda), presented once in real time and recorded for broadcast online. This approach brings the dynamics of difference and negotiation between theatrical aesthetic settings. Based on the Matrix Method (Jacob Ginsburg and Rubens Brito), a group of works by the director Gerald Thomas composed the material of analysis. The element-procedure for the recreation of the creative matrix (tendency to false) was the blognovel from the event "The first blognovel of the history: the dog who insulted women, kepler, the dog". The categories (methodology, creation process, theatrical poetics) become reversible and temporary positions in the context of the tendency to false.

Keywords: Theatrical Theory, Notions of Presence, Narratives.

\section{Resumen}

LA SEGUNDA HISTORIA BLOGNOVELA: AUTOBIOGRAFÍA. IMPERSONAL., Erlon Cherque y Guilherme Miranda, puesta en escena una vez en tiempo real y grabado para su difusión en-línea. Basado en el método de la matriz (Jacob Guinsburg y Rubens Brito), estableció la agrupación de los trabajos del Director Gerald Thomas. La matriz creativa resultante: tendencia a la falsificación. El elemento del procedimiento de interés para recrear la matriz creativa (tendencia a la falsificación) era la blognovela en el evento titulado "la primera blognovela de la historia: el perro que insultar a las mujeres, kepler, el perro". Las categorías (metodología, proceso de creación teatral y poética) se convierten en puestos temporales y reversibles en el contexto de la tendencia a la falsificación.

Palabras-clave: Teatro contemporáneo, estética de la falsificación, narrativas.

1 Doutor em Teatro pela UNIRIO e Professor Adjunto, Departamento de Artes Cênicas daUFPB, coordena o Grupo de Pesquisa A Poética Cênico-dramatúrgico Conjugada e o projeto de extensão Mascate, Laboratório de Teatro Contemporâneo Itinerante. 
Diante do enorme sucesso da primeira edição, lançou-se A SEGUNDA BLOGNOVELA DA HISTÓRIA: AUTOBIOGRAFIA. IMPESSOAL. Verdade ou mentira, a forma de anúncio publicitário abrange certo caráter verossímil (aparência de verdade), gerando credibilidade. No contexto da sociedade de consumo, destaca-se a ânsia veloz e incessante pelo novo. Assim, o apelo ao inédito entra em conflito com o segundo lugar. Considerando o ideal competitivo da lógica de mercado, o destaque cabe exclusivamente ao número 1. Somente o vitorioso recebe os lucros expressivos ou o grande prêmio. "A SEGUNDA (vez)" indica desgaste, cancelando a informação anterior de aparente novidade. Este ineditismo perdido afeta o crédito por deixar os anseios de consumo insatisfeitos e/ou frustrados. ${ }^{2}$

A expressão 'enorme sucesso' sugere ampla divulgação, relevância e reconhecimento inquestionáveis. $\mathrm{Na}$ abertura, a ênfase é reforçada pelo complemento DA HISTÓRIA. Apesar da pretensa aclamação pública, o efeito de espetáculo parece sobrescrever-se à própria mensagem. Prova disso, permanece a dúvida: o que é uma blognovela? Para responder, o leitor-espectador é remetido ao primeiro acontecimento. Perguntar 'o que é?' envolve traduzir, especificar ou esclarecer algo. Em lugar do significado ou da explicação de blognovela aponta-se para outro termo/expressão: no caso, A PRIMEIRA BLOGNOVELA apresenta valor de código porque continua (ou reforça) a indagação ‘o que é a blognovela?'. Dentre outras possibilidades de leitura, destaca-se: 'Certo, ocorreu uma primeira blognovela. Mas, o que é? Quais as características? Cor, forma, matéria ou materiais e conteúdo? É parecido com o quê? E as diferenças?'

Assim, procurar o significado é um processo que envolve diferentes graus de afinidade e/ou distância entre seus fatores constituintes (signos). Por exemplo - gato é um animal de quatro patas. Cão, animal e tem quatro patas. Neste ponto, cão e gato se aproximam. Mas, gato mia e cão late. Aqui ambos se afastam. Porém, cães e gatos estão mais próximos entre si que de uma planta. Na última, as patas estão ausentes e da espécie animal passa-se à vegetal. Ainda que minimamente, apresentaram-se características de cão e gato por aproximação e distanciamento. De maneira breve, o exemplo ilustra possíveis entendimentos sobre processos de atribuição de significado (o que significa?) a partir do relacionamento e da diferença entre significados conhecidos (explicações ou características disponíveis) e desconhecidos (ainda não esclarecidos ou traduzidos).

2 A presente reflexão articula-se com a comunicação oral apresentada no III ComA, linha Processos Composicionais para a Cena, Programa de Pós-Graduação em Arte, Instituto de Artes, Universidade Federal de Brasília (UnB). 
Se a tarefa de esclarecer baseia-se em semelhanças e afastamentos, resta descobrir qual o intuito de associar significados desconhecidos. Ainda outra peculiaridade, as expressões PRIMEIRA BLOGNOVELA e SEGUNDA BLOGNOVELA revelam a ocorrência do igual: a blognovela. Porém, este idêntico (blognovela) é tratado como outro na explicação sobre o desconhecido. Nota-se o mesmo ou idêntico na expressão A PRIMEIRA BLOGNOVELA (re)formulada, disfarçada e/ou deformada na aparência de outro na SEGUNDA BLOGNOVELA. Ao simular o contraste entre falsos-idênticos e/ ou falsos-outros, destaca-se a impressão ou aspecto de explicação ou esclarecimento. Antes de respostas definitivas, trata-se de chamar atenção para os atritos e espaços vazios entre os significados.

Solucionar tais paradoxos ou retificar contradições e ambiguidades abrange explicar 'o que significa?'. Porém, o excesso e o acúmulo de informações (internet, convergência de meios e transportes) constituem noções de tempo e espaço marcadas pela velocidade. É possível compreender que os movimentos se tornam cada vez mais rápidos. Assim, a acelerada dinâmica temporal parece seguir na direção oposta à postura contemplativa verificada na observação de fatos, reflexão e explicação ou esclarecimento. Dentre outras consequências, surge a tendência ao esvaziamento de significados e/ou significados problemáticos. Se a fábula aproxima-se da estrutura dos significados (o que significa?), a blognovela se interessa pelo falso-idêntico ou falso-outro a (re)formular ou deturpar formas e conteúdos fabulares.

A primeira imagem desta AUTOBIOGRAFIA. IMPESSOAL é marcada pela falta: ausência ou insuficiência de luz. Após o som de um explosão, o título é projetado em uma tela inclinada. Este ângulo torna a observação frontal precária, sugerindo que o espectador sente-se no chão. A partir do roteiro da cena-performance, a cena-quadro prossegue da seguinte maneira:

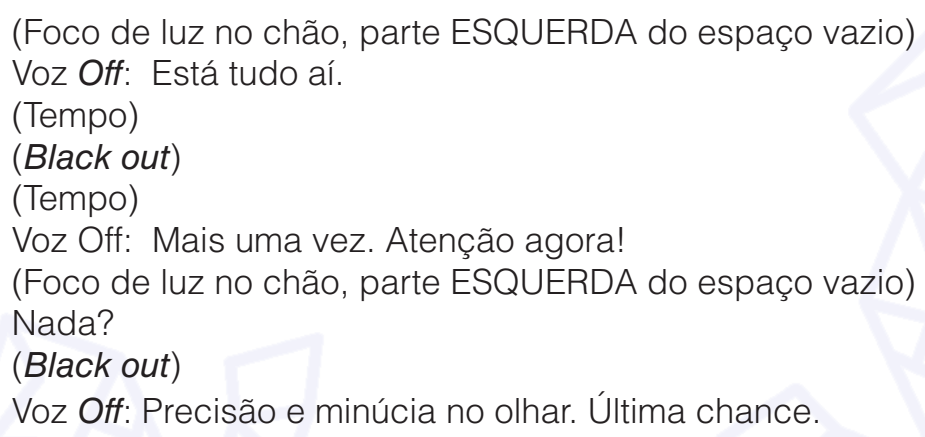

Considerando o recorte deste momento inicial, percebe-se o jogo entre camadas de luz, penumbra e escuridão. Em lugar do significado claro (esclarecido ou sob a 
iluminação), percebem-se sensações ou estímulos sonoros e visuais em interação com a imaginação do espectador. Na configuração tradicional ou ideal da fábula, o assunto ou tema principal aparece no título, indicação esta ausente ou falha na blognovela pela referência à PRIMEIRA BLOGNOVELA ou a palavras marcadas pela contradição e ambiguidade: AUTOBIOGRAFIA. IMPESSOAL. Assim, a atividade criativa do espectador é solicitada desde a leitura do título - forma de esclarecimento (o que significa?) em atrito com conteúdos obscuros (esvaziamento dos significados ou significação problemática), na escuridão. Aqui a aceleração nas dinâmicas de tempo e espaço abrange a ausência de figura humana em cena.

A Voz Off passa de vestígio de presença a presença atual no aqui e agora da encenação, rompendo os limites claros entre passado e presente. Ao dizer 'Está tudo aí', a camada sonora torna-se jogo com o efeito de atrito entre explicar (claro) e ocultar (escuro) também na composição imagética. Uma voz que não se sabe de quem e nem de onde (obscuro) diz que está tudo no palco em contradição com um foco que ilumina um espaço vazio. Trata-se de enfatizar a própria atividade do olhar do espectador, sublinhar o confronto com o horizonte de leituras/espetáculos marcado por significados plenos e claros - Cadê os personagens? E o protagonista, quem é? Ele luta contra quem? Com qual objetivo? Seus aliados e inimigos? Como vencerá os obstáculos? Onde e quando se passa a história?

Mesmo com o palco vazio, está tudo ali... na mente do espectador por uma tradição de leituras e de dramaturgia. Entre os significados Teatro e Blognovela, a semelhança inclui o palco e seus funcionamentos técnicos, além da demarcação entre área de jogo e espectador. Este traço comum favorece a expectativa pela estruturação da fábula baseada na história contada pela ação entre personagens. Elementos da estética teatral aparecem disfarçados, deturpados e (re)formulados na forma (aparência) de outro - Blognovela. Sobe o espaço de atrito ou vazio entre Teatro e Blognovela, a Voz Off constitui-se em falso-idêntico ou idêntico-falso em sua insuficiência caracterizada pela ausência da figura humana correspondente. Cabe refletir se basta a presença do corpo para reestabelecer a atribuição de significados ou resposta em termos de 'o que significa?'. A cena prossegue da seguinte maneira:

(Foco de luz no chão, parte DIREITA do espaço ilumina uma das mãos) A mão realiza um gesto.

Voz Off: O que é isso? Talvez um chamado... um convite. Para quem sabe... Quem sabe... Mostrar algo escondido. Lá no fundo, no escuro.

(Repentinamente, a sala é tomada por muita luz por um breve momento com o intuito de provocar alteração na visão do público. Logo após o acendimento 


\begin{abstract}
abrupto, um grito que deve durar até a luz se apagar novamente. Ao apagar as luzes, uma projeção na parede com o restante da sala no escuro. A boca dubla o grito e ao terminar o som, ela permanece com a dublagem por uns segundos. Após isso, um flash e a nova imagem é o close dos olhos que deve permanecer durante a fala seguinte).

Voz Off: Então é isso. Viver incomoda. Dói, não é?

Voz Off: Então é isso. Viver incomoda (tom entre malicioso, irônico e cruel). Dói, não é? (Docilidade, amabilidade e compreensão).

Voz Off: Então é isso (Descoberta e conclusão). Viver incomoda. (raiva) Dói, não é? (Interrogatório).
\end{abstract}

Conforme o trecho do roteiro, o corpo está aos pedaços: a mão sob o foco de luz, a boca e os olhos na projeção. Se parece haver rompimento com a ideia de organismo ou inteiro (corpo), cada parte realiza ações: a mão realiza o gesto de chamado, a boca dubla o grito e os olhos observam um objeto. A exemplo da Voz Off, os fragmentos se comportam como se fossem figuras humanas individualizadas. Porém, o espectador permanece sem saber para que foi chamado. Também ignora o motivo do grito, a mudez da boca ou por quê os olhos em close observam os espectadores. Além de faltar uma ligação entre tais sensações sonoras e visuais. Percebe-se certo caráter de incompleto ou de falha, constituindo-se em falso-idêntico ou outro-falso. Esta posição intermediária entre idêntico e outro abrange o elemento-chave na constituição da fábula: a ação. $O$ que torna este igual também outro é recorrer à ação, alterando a sua função.

$\mathrm{Na}$ fábula, as personagens só realizam ações de relevância para narrar a história ou intriga. O trecho do roteiro de AUTOBIOGRAFIA. IMPESSOAL cita ou refere-se a esta aparência de propósito de ações, mas os conteúdos tornam-se vazios e/ou problemáticos: Chamar para quê? Gritar por quê? E a separação entre o som do grito e a expressão visual do grito? A inversão entre olhar e ser visto. Ao recorrer ao mesmo (idêntico) com função alterada/deturpada, notam-se possíveis relacionamentos entre tradição e contemporaneidade teatral para além de classificações ou explicações baseadas no esclarecimento ou atribuição de significado (o que significa?). Outro elemento da fábula, a própria noção de personagem parece associada à ideia de indivíduo - indivisível, particular, uno e único. Na apreciação anterior, conciliou-se divisão/ fragmentação do particular a graus de permanência da autonomia de indivíduo nas partes. Já no recorte abaixo, percebe-se ainda outra configuração:

Foco apenas no rosto de um homem, pode ser uma lanterna. Ele masca chiclete.

Voz Off (muda de voz): Por isso, as ilusões são necessárias.

Voz Off (muda de voz): Por isso, as ilusões são imprescindíveis.

Voz Off (muda de voz): Por isso, as ilusões são urgentes.

Voz Off (muda de voz): Por isso, as ilusões são patéticas.

Voz Off (muda de voz): Por isso, as ilusões são decadentes. 


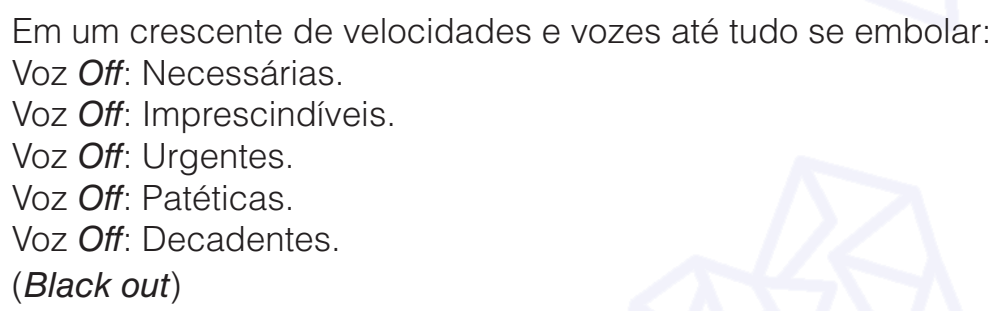

Aqui, surge um rosto no escuro. Ainda que se trate de outra parte, um rosto apresenta especificidades e elementos únicos. Se a mão do quadro anterior pode ser confundida com qualquer outra mão de um conjunto, torna-se mais difícil ocorrer o mesmo com esta face diante de outras. O procedimento de iluminar somente o rosto aproxima-se do close ao destacar e exagerar o detalhe, supostamente as características únicas do rosto em foco. Percebe-se o cruzamento entre as camadas cinema (pelo close) e teatro (conforme as propriedades do palco). Enquanto cinema e vídeo apresentam imagens sobre superfícies planas (parede ou monitor), o teatro compõe-se pela perspectiva e em perspectiva. Ao se passar do teatro ao cinema ou vice-versa, ocorrem transformações e adaptações.

No último trecho do quadro descrito no roteiro, iluminar somente o rosto em cena diante do escuro delimita e destaca este objeto. Por outro lado, o excesso de luz na parte acaba por apagar ou tornar menos discernível o detalhe. Como resultado, o close torna-se falso perante a alteração de uma porção de sua função: o destaque deveria favorecer o detalhe, mas acaba por eliminar ou reduzir suas diferenças. Deste modo, a expectativa de identidade (rosto considerado marco do único) altera-se para generalidade inesperada ou impessoal (apenas mais um rosto dentre outros, semeIhante à mão).

Antes de buscar respostas para 'o quê significa?' (atribuir significado), os quadros acima descritos e as possíveis leituras sugeridas perseguem atritos e vazios entre significados. Se a noção estrita de fábula baseia-se em significados, o falso-idêntico ou outro-falso em AUTOBIOGRAFIA.IMPESSOAL privilegia o desconhecimento ou impossibilidade de decidir entre originais e cópias, imagem e sombra ou claro e escuro. Neste contexto, esta possível poética teatral mantém-se processo com o espectador ao reconhecer o idêntico e reformular o próprio julgamento ao notar sua dimensão de falso. Para cumprir este objetivo, recorreu-se à BLOGNOVELA pela aproximação com a obra de Gerald Thomas intitulada 'A PRIMEIRA BLOGNOVELA DA HISTÓRIA: O CÃO QUE INSULTAVA MULHERES. KEPLER, THE DOG.' 
A aproximação mencionada ocorreu conforme indicações de Rubens Brito e Jacó Guinsburg sobre o Método Matricial, conceito elaborado a partir da investigação dos procedimentos criativos de Luis Alberto de Abreu. Trata-se de proposta metodológica de pesquisa em dramaturgia, aplicável a outras áreas das Artes Cênicas. O estudo de Rubens Brito e Jacó Guinsburg evidencia a busca de padrões de criação no interior do próprio objeto estético. Neste contexto, o investigador recria o objeto estético e também o próprio olhar ao desenvolver estratégias de leitura específicas para cada elemento/procedimento por ele identificados.

Incialmente definem-se as fontes primárias. Neste caso, considerou-se três obras de Gerald Thomas: 'The flash and the crash days', 'Esperando Beckett' ' 'Kepler,The dog'. Em seguida, o aprofundamento em cada obra. Então, buscam-se recursos comuns e diferenciados entre os diferentes materiais. Conforme as características identificadas, percebe-se de que maneira tais elementos-procedimentos aparecem com maior ou menor frequência nas obras selecionadas. De acordo com as maneiras pelas quais as relações e qualidades entre os elementos-procedimentos constituem modos de composição da obra, estabelece-se a matriz criativa. Nas obras consideradas, identificou-se a matriz criativa tendência ao falso. Estabeleceu-se que em 'Kepler, The dog', o elemento-procedimento blognovela reforçava a tendência ao falso (matriz criativa) por valer-se da hipermídia para intensificar o atrito e vazio entre significados.

\section{Referências bibliográficas}

AUGÉ, Marc. Não-lugares. Introdução a uma antropologia da supermodernidade. São Paulo: Papirus, 2005.

BONFITTO, Matteo. $\mathbf{O}$ ator compositor: as ações físicas como eixo: de Stanisláviski a Barba. São Paulo: Perspectiva, 2002.

BORNHEIM, Gerd A. O sentido e a máscara. São Paulo: Perspectiva, 1975.

BRITO, Rubens; GUINSBURG, Jacó. Método Matricial (18-25). In CARREIRA, André; CABRAL, Biange; RAMOS, Luiz Fernando; FARIAS, Sérgio Coelho (Orgs.). Metodologias de pesquisa em artes cênicas. Rio de Janeiro:7 Letras, 2006.

CARLSON, Marvin. Teorias do teatro: estudo histórico-crítico, dos gregos à atualidade. São Paulo: UNESP, 1997.

DEBORD, Guy. A sociedade do espetáculo. Rio de Janeiro: Contraponto, 1997.

FISCHER, Ernst. A necessidade da arte. Rio de Janeiro: Guanabara Koogan, 2002.

GLUSBERG, Jorge. A arte da performance. São Paulo: Perspectiva, 1987.

GUMBRECHT, Hans Ulrich. Modernização dos sentidos. São Paulo: Ed. 34: 1998.

GUIMBUSBURG, J. (org.). Semiologia do Teatro. São Paulo: Perspectiva, 1978. 
; BARBOSA, Ana Mae. O pós-modernismo. São Paulo: Perspectiva, 2005.

HALL, Stuart. A identidade cultural na pós-modernidade. Rio de Janeiro: DP\&A, 2005.

JAMESON, Frederic. O método Brecht. Rio de Janeiro: Vozes, 1999.

LIMA, Luiz Costa. Mímesis: desafio ao pensamento. Rio de Janeiro: Civilização Brasileira, 2000.

PAVIS, Patrice. Dicionário de teatro. São Paulo: Perspectiva, 1999.

PINTO, Erlon Cherque. Gerald Thomas apresenta: a primeira blognovela da história "o cão que insultava mulheres, kepler, the dog. Notas sobre questões de gênero artístico sexual. Rio Grande do Sul, Cena, v.2, n. 10, p.3-23, 2011.

\section{Referências teatrais}

A segunda blognovela da história

\section{Autobiografia. Impessoal}

Direção: Erlon Cherque e Guilherme Miranda

Operação de som e imagem: Leonardo Miranda

Elenco: Erlon Cherque e Guilherme Miranda

Centro Cultural da Justiça Federal do Rio de Janeiro

\section{A primeira blognovela da história}

\section{O cão que insultava mulheres, kepler, the dog}

Som: Claudia Dorei Produção: Plato Produções (Dora Leão) Assistência: Ivan Andrade. Realização SESC unidade Av. Paulista. Direção: Gerald Thomas Elenco: Fabiana Gugli, Pancho Capelletti, Duda Mamberti, Anna Américo, Luciana Froes, Simone Martins, Caca Manica, Luz: Caetano Vilela. 